\title{
Effects upon Substitution in Alkali Metal Thallides: How far can X-Ray Structure Determination of Strongly Absorbing Compounds go?
}

\author{
Dr. Stefanie Gärtner ${ }^{1,2}$, Vanessa Schwinghammer ${ }^{1}$ \\ ${ }^{1}$ Institute of Inorganic Chemistry, University of Regensburg, Germany \\ ${ }^{2}$ Department X-Ray-Structure Analysis, Central Analytical Services, University of Regensburg, Germany
}

Stefanie.gaertner@uni-regensburg.de

Compounds including thallium in formal negative oxidation states have been known since Zintl stated the existence of $\mathrm{NaTl}$ in the 1930s [1]. In the 1980s and 1990s, binary materials of alkali metal and thallium have been characterized [2] but crystal structures always suffered from severe absorption effects due to very large absorption coefficients for these kinds of materials. This fact for a long time was equitable to the physical frontier of the method of structure determination for these element combinations. Nowadays, for these compounds, which were formerly assumed to behave rather as a primary beam stop, very good data sets can be realized due to highly resolving detectors and intensive x-ray sources [3]. This is the pre-condition for a renaissance of investigations on alkali metal thallides. The amount of alkali metal does not readily suggest the formed thallium sublattice. In fact, one can find transitions between different type structures in dependence of the more electropositive element involved. Looking at the already known alkali metal thallide compounds, it is striking that some gaps still have remained [4]. For example, in $\mathrm{A}_{15} \mathrm{Tl}_{27}(\mathrm{~A}=\mathrm{Rb}, \mathrm{Cs})$ [5] and $\mathrm{K}_{49} \mathrm{Tl}_{108}$ [6] type structures, the ratio of alkali metal : thallium is very similar, but the respective crystal structures severely differ. While $\mathrm{K}_{49} \mathrm{Tl}_{108}$ is a complex cubic compound including a three-dimensional sublattice of thallium, $\mathrm{A}_{15} \mathrm{Tl}_{27}$ involves $\mathrm{Tl}_{11}{ }^{7-}$ clusters and twodimensional thallium layers. Here, partially occupied alkali metal Wyckoff sites allow for the discussion of their effect on the observed thallium sublattice (Figure 1). Additionally, the possibility of partially replacing cesium by thallium could be demonstrated for the new binary material $\mathrm{Cs}_{14.53} \mathrm{Tl}_{28.4}$ in terms of an ordered substitution variant of $\mathrm{Cs}_{15} \mathrm{Tl}_{27}$ (Figure 2).

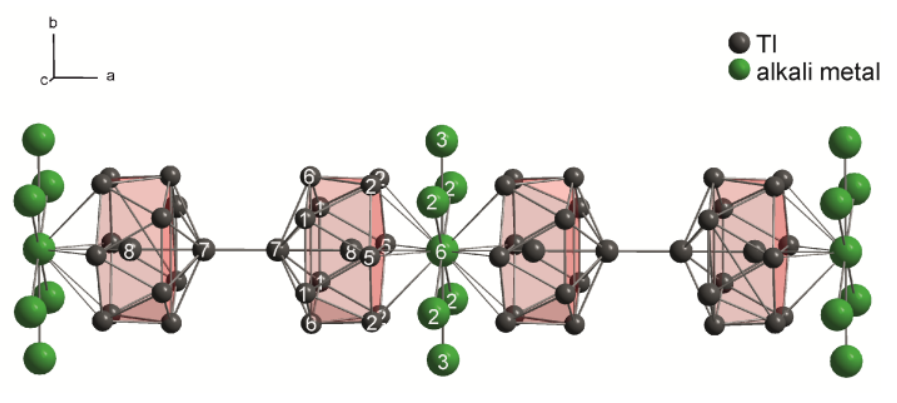

Figure 1. Mixed occupied alkali metal sites directly influence the T17-Tl7 distance within the Tl-sublattice in $\mathrm{A}_{49} \mathrm{Tl}_{108}$ (only part of the structure is given).

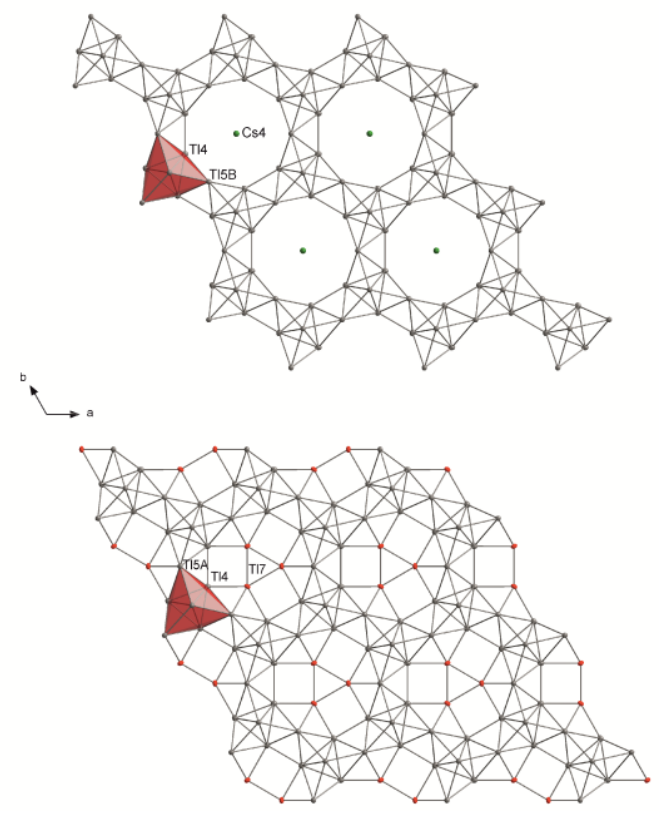

Figure 2. (Partial) replacement of Cs4 in $\mathrm{Cs}_{15} \mathrm{Tl}_{27}$ by $\mathrm{T} 17$ yields a formally oxidized $\mathrm{Tl}$-layer in $\mathrm{Cs}_{14.53} \mathrm{Tl}_{28.4}$. 
[1] E. Zintl and W. Dullenkopf, Z. phys. Chem. 1932, B16, 195-205; S. M. Tiefenthaler, M. Schlosser, F. Pielnhofer, I. G. Shenderovich, A. Pfitzner and S. Gärtner, Z.Anorg.Allg. Chem. 2020, 646, 82-87; S. Tiefenthaler, N. Korber and S. Gärtner, Materials $2019,12$.

[2] J. D. Corbett, Angew. Chem. Int. Ed. 2000, 39, 670-690.

[3] S. Gärtner, S. Tiefenthaler, N. Korber, S. Stempfhuber and B. Hischa, Crystals 2018, 8.

[4] S. Gärtner, Crystals 2020, 10(11), 1013.

[5] Z. C. Dong and J. D. Corbett, Inorg. Chem. 1996, 35, 1444-1450.

[6] G. Cordier, V. Müller and R. Fröhlich, Z. Kristallogr. 1993, 203, 148-149.

Keywords: x-ray structure determination; high absorption coefficients; thallides; alkali metal; Zintl phases. 